\title{
Enumeration of Paneth cells in coeliac disease: comparison of conventional light microscopy and immunofluorescence staining for lysozyme
}

\author{
H SCOTT* AND P BRANDTZAEG
}

From the Histochemical Laboratory, Institute of Pathology, the National Hospital, Rikshospitalet, Oslo, Norway

SUMmary By conventional light microscopy, a reduced number of Paneth cells per intestinal crypt was found in the jejunal mucosa of patients with untreated or gluten-challenged coeliac disease as compared with histologically normal control specimens. A much better detection sensitivity was obtained when Paneth cells were counted by fluorescence microscopy after immunostaining for lysozyme with a rhodamine-labelled rabbit IgG conjugate. This method showed that there was no numerical reduction of Paneth cells in coeliac disease, but that the proportion of cells with a low lysozyme content was increased. Most of these cells were probably missed by conventional microscopy in which identification of Paneth cells is principally based on a substantial cellular complement of acidophilic granules. A reduced number of lysozymecontaining granules in coeliac disease may reflect increased discharge, enhanced secretory activity, or a raised turnover of the Paneth cells.

The Paneth cells are secretory epithelial cells localised at the base of the small intestinal crypts. They are the main source of jejunal lysozyme (muramidase), ${ }^{1-5}$ which is an enzyme with bactericidal" i and antiviral" activity. It has, therefore, been suggested that the Paneth cells participate in the anti-microbial defence of the intestinal crypts. ${ }^{1}$

Jejunal mucosa of patients with coeliac disease has by some authors been reported to contain fewer Paneth cells per crypt than normal, " $" 10$ and this reduction was found to persist in patients on a gluten-free diet when the mucosa had otherwise recovered. "However, there has been considerable dispute concerning overall Paneth cell changes in coeliac disease, as discussed in a recent review. ${ }^{11}$

The aim of this study was to establish whether the state of the Paneth cells is a practical indicator of gluten sensitivity as evaluated by enumeration of Paneth cells per intestinal crypt and by taking their lysozyme content into account. Specimens of jejunal mucosa with various degrees of villous atrophy, obtained from patients with coeliac disease, were compared with an apparently normal control material.

*Address for correspondence: Dr H Scott, Histochemical Laboratory, Institute of Pathology, Rikshospitalet, Oslo 1, Norway.

Received for publication 29 April 1981

\section{Methods}

PATIENTS

Control subjects

Seven males, eight females (median age, 39 years; range, 3-77 years) with a histologically normal jejunal mucosa were included; in three cases colon carcinoma, motor neuron disease, or psoriasis was diagnosed, respectively, whereas the remaining 12 had no detectable organic disease despite abdominal complaints.

\section{Coeliac disease in remission}

Three males, 12 females (median age, 10 years; range, 2-52 years) with proven coeliac disease were included. They had received a gluten free diet for a median period of three years (range one to nine years). Their jejunal mucosa showed no histopathological alterations (four cases) or partial villous atrophy (11 cases).

Untreated or gluten-challenged coeliac disease Six males, nine females (median age, 20 years; range, 4-71 years) with clinically overt coeliac disease at the time of biopsy were included. Their mucosa showed subtotal to total villous atrophy. 


\section{METHODOLOGY}

The mucosal biopsy specimens were fixed in $4 \%$ formalin and processed by the routine method of our pathology department. ". Paraffin sections were cut serially at $6 \mu \mathrm{m}$ and numbered $1-4$. After deparaffinisation, sections 1 and 3 were stained by haematoxylin, asophloxine, and saffron (HAS). ${ }^{13}$ Sections 2 and 4 were subjected to pronase treatment followed by immunofluorescence staining for lysozyme as detailed elsewhere. ${ }^{14}$ The fluorochrome conjugate was a monospecific rabbit IgG labelled with tetramethylrhodamine isothiocyanate in our laboratory according to established procedures. ${ }^{1 .}$ The characteristics of this conjugate have been reported previously. ${ }^{14}$ It was applied at a concentration of $0.15 \mathrm{~g} \mathrm{IgG/1}$ for 20 hours at room temperature.

PANETH CELL COUNTING

The study was based on tissue sections in which the intestinal crypts were oriented reasonably perpendicular to the muscularis mucosae. All crypts (between 15 and 84 ) in every section were evaluated with regard to Paneth cells. The senior investigator was responsible for the cell counting throughout the study.

The HAS-stained sections were examined by conventional light microscopy using a $\times 40$ objective and a $\times 10$ ocular. Crypt cells that contained red granules and showed a distinct nucleus were enumerated.

The immunostained sections were examined by fluorescence microscopy with a Leitz Orthoplan microscope equipped with a Ploem-type vertical illuminator; excitation and selective filtration conditions for rhodamine, a $\times 25$ immersion objective, and a $\times 10$ ocular were used. Paneth cells were counted and recorded in two categories according to fluorescence intensity (faint or bright). Fluorescent crypt cells that showed morphology and size characteristic of Paneth cells were included whether a nucleus could be identified or not. Smaller cell profiles were included only when they contained a distinct nucleus (Fig. 1). Lysozyme-containing cells in the lamina propria ${ }^{11}$ were stained quite faintly with the working concentration of the anti-lysozyme reagent used in this study; they were easily distinguished from Paneth cells both because of different localisation and staining properties.

STATISTICAL METHODS

Every specimen was evaluated by both HASstaining and immuno-staining. For each section the total number of Paneth cells recorded by either

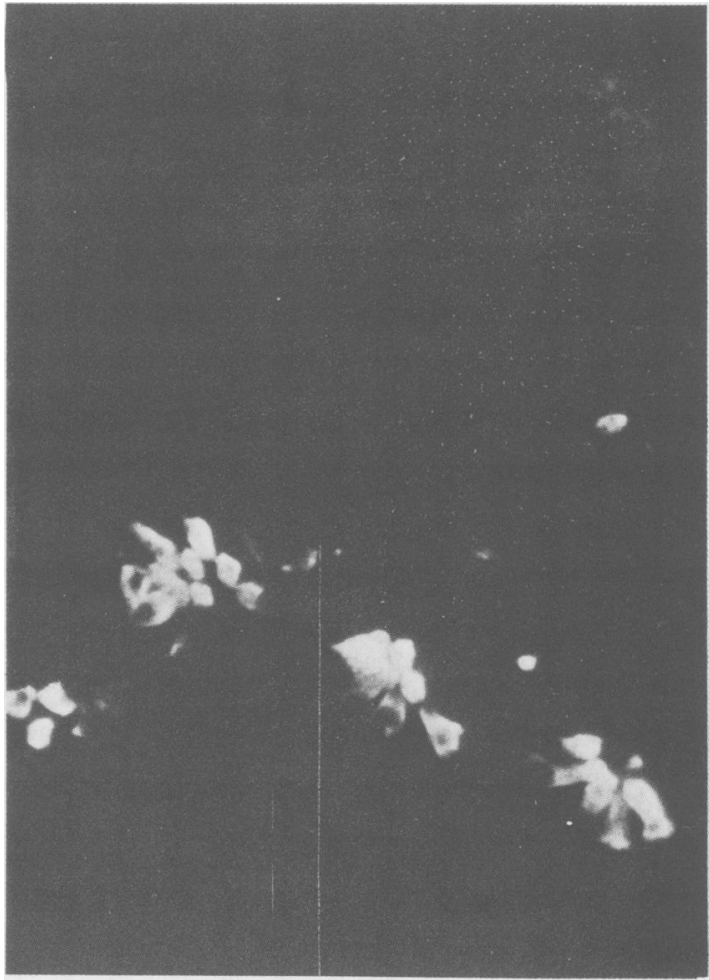

Fig. 1 Direct immunofluorescence staining of Panet." cells at the base of the crypts in a section of normal jejunal mucosa. Ly'sozyme-containing cells in the lamina propria were too faintly stained to be shown with the exposure time used here. Gut lumen at the top. Magnification, $\times 400$.

method was divided by the number of crypts and the result was expressed as Paneth cells per crypt. The mean results obtained from duplicate sections were used in group calculations. Differences between methods were evaluated by Wilcoxon's test for paired samples, and between groups by Wilcoxon's test for unpaired samples.

\section{REPRODUCIBIL IT Y}

Cell counts were repeated in 10 specimens after at least six weeks by the senior investigator; the data showed a mean coefficient of variation $(C V \pm S D)$ of $8 \cdot 2 \pm 5 \cdot 5$ for Paneth cells per crypt as evaluated by conventional microscopy; $14 \cdot 6 \pm 7 \cdot 2$ for Paneth cells per crypt as evaluated by immunostaining; and $14 \cdot 7 \pm 10.8$ for the proportion of Paneth cells that showed faint fluorescence staining. 


\section{Results}

PANETH CELLS RECORDED BY CONVENTIONAL LIGHT MICROSCOPY

The observed range for Paneth cells per crypt was relatively large and overlapped markedly among the three categories of subjects (Fig. 2). When patients with coeliac disease in remission were compared with controls, no difference in the number of Paneth cells per crypt was found. However, patients with untreated or gluten-challenged coeliac disease contained significantly fewer Paneth cells $(\mathrm{P}<0.005)$.

\section{PANETH CELLS RECORDED BY}

F LUORESCENCE IMMUNOSTAINING

With this method a significantly higher number of Paneth cells $(P<0.001)$ was found in all categories of subjects compared with the light microscopical results, but there was no significant difference in the total number of immunostained cells between the three groups (Fig. 2). However, compared with controls, the percentages of faintly

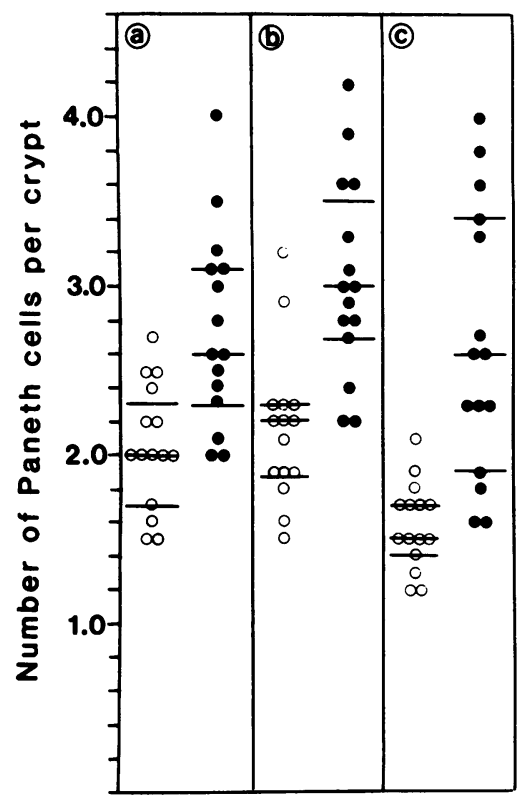

Fig. 2 The number of Paneth cells per crypt in jejunal mucosa from controls $(a)$, coeliac disease patients in remission on a gluten-free diet (b), and untreated or gluten-challenged $C D$ patients $(c)$ recorded by conventional microscopy $(\mathrm{O})$ and by lysozyme immunofluorescence (O). Median with 25 and 75 percentiles are indicated by horizontal lines. stained cells (Fig. 3) were higher both in patients with coeliac disease in remission $(P<0.05)$ and in the untreated or gluten-challenged patients with coeliac disease $(\mathrm{P}<0.001)$.

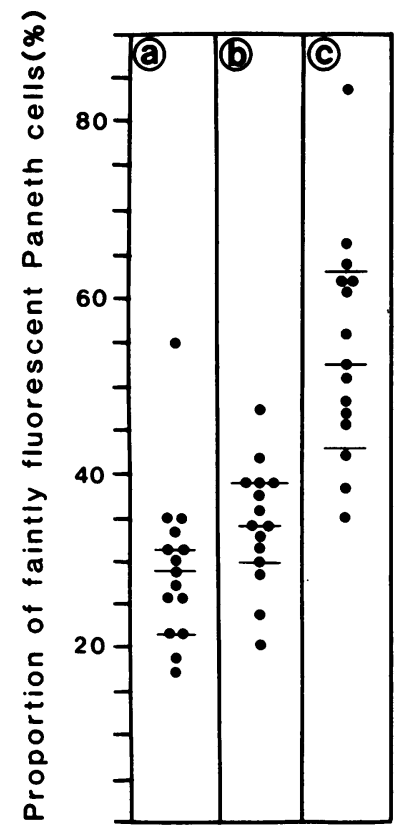

Fig. 3 Percentage of Paneth cells showing faint fluorescence staining for lysozyme in jejunal mucosa from controls (a), coeliac disease patients in remission on a gluten free diet $(b)$, and untreated or gluten challenged coeliac disease patients $(c)$. Median with 25 and 75 percentiles are indicated by horizontal lines.

\section{Discussion}

By conventional light microscopy, a reduced number of Paneth cells per crypt seemed to be present in the jejunal mucosa of untreated or glutenchallenged patients with coeliac disease as compared with histologically normal controls. This result is in agreement with some previous studies, ${ }^{5910}$ but we could not confirm that patients with coeliac disease in remission had a reduced number of Paneth cells. ${ }^{5}$

The detection sensitivity was considerably enhanced when Paneth cell enumerations were based on direct immunofluorescence staining of lysozyme with a rhodamine conjugate and prolonged incubation time. ${ }^{14}$ By this method no significant difference in the numbers of Paneth cells per crypt was found among the three categories of specimens studied. By conventional light microscopy Paneth cells are identified principally by 
their characteristic acidophilic granules in which most of the cytoplasmic lysozyme is localised. ${ }^{17}$ Paneth cells with a reduced number of granules will be difficult to recognise, and immunostaining showed that the jejunal mucosa of coeliac disease patients contained an increased proportion of Paneth cells with a low content of lysozyme. Most of these cells would probably escape recording by conventional light microscopy.

Reduced extractable lysozyme activity per $\mathrm{mg}$ wet weight of jejunal mucosa has been reported in coeliac disease. ${ }^{5}$ This is in accordance with our immunohistochemcial staining results for Paneth cells. However, in the evaluation of extractable activity the changes in mucosal mass related to coeliac disease were not taken into account and a contribution of lysozyme by infiltrating inflammatory cells was not fully excluded.

Paneth cells have been shown in mice to discharge their granules after pilocarpine $e^{4819}$ and carbachol $^{20}$ stimulation.

Our immunohistochemical observation of a raised proportion of Paneth cells with a low lyso'zyme content in patients with coeliac disease could have resulted from an increased sensitivity of the cells to some chemical stimulus or be caused by a lysosomal membrane instability as suggested by Ward et al. ${ }^{5}$ But it might also reflect the increased division of crypt cells in coeliac disease ${ }^{2122}$ or an influence of mucosal inflammation on these cells.

A decreased cytoplasmic lysozyme content is not necessarily a sign of reduced Paneth ce!l activity. If the enzyme is rapidly secreted instead of being stored in the granules, the cell may have a normal or even an increased production of lysozyme. A raised serum lysozyme activity in patients with coeliac disease ${ }^{23}$ is perhaps in agreement with the latter possibility, but it is not possible to know the relative contributions from inflammatory cells and Paneth cells to the circulating pool of lysozyme.

\section{Conclusions}

There is no numerical reduction of jejunal Paneth cells in coeliac disease, although the proportion of cells with a high content of lysozyme is decreased. This finding does not necessarily indicate that the production of lysozyme in Paneth cells is hampered in coeliac disease, but may rather reflect an increased secretion of the enzyme or a raised turnover of the cells.

We thank Olav Fausa, MD, for valuable cooperation and Ms Gunn Jamne, Ms Vigdis
Wendel, and the staff of the Laboratory of Gastroenterology for technical assistance. This study was supported in part by Anders Jahre's Foundation.

\section{References}

1Deckx BJ, Vantrappen GR, Parcin MM. Localization of lysozyme activity in a Paneth cell granule fraction. Biochim Biophys Acta 1967: 139:204-7.

${ }^{2}$ Ghoos Y, Vantrappen G. The localization of lysozyme in Paneth cell granules. Histochem J 1971; 3: 175-8.

${ }^{3}$ Geyer G. Lysozyme in Paneth cell secretions. Acta Histochem (Jena) 1973; 45:126-32.

${ }^{4}$ Peeters T, Vantrappen G. The Paneth cell: a source of intestinal lysozyme. Gut 1975; 16:553-8.

"Ward M, Ferguson A, Eastwood MA. Jejunal lysozyme activity and the Paneth cell in coeliac disease. Gut 1979; 20:55-8.

Chipman DM, Sharon N. Mechanism of lysozyme action. Science 1969; 165:454-65.

${ }^{7}$ Bladen H, Hageage G, Harr T, Pollock F. Lysis of certain organisms by the synergistic action of complement and lysozyme. J Dent Res 1973; 52: 371-6.

${ }^{8}$ Ribble JC, Hook EW. Inactivation of bacteriophage by lysozyme (Abstract). Fed Proc 1959; 18:594.

'Creamer B, Pink IJ. Paneth-cell deficiency. Lancet 1967; 1:304-6.

${ }^{10}$ Lewin K. The Paneth cell in disease. Gut 1969; 10: 804-11.

${ }_{11}$ Sandow MJ, Whitehead R. Progress report. The Paneth cell. Gut 1979; 20:420-31.

${ }^{12}$ Rognum TO, Brandtzaeg P, Ørjasaeter H, Fausa $O$. Immunohistochemistry of epithelial cell markers in normal and pathological colon mucosa. Comparison of results based on routine formalin- and cold ethanol-fixation methods. Histochemistry 1980; 67: 7-21.

${ }^{13}$ Stave R, Brandtzaeg P. Fluorescence staining of gastric mucosa. A study with special reference to parietal cells. Scand J Gastroenterol 1977; 12:88591.

${ }^{14}$ Brandtzaeg $P$. Prolonged incubation time in immunohistochemistry: effects on fluorescence staining of immunoglobulins and epithelial components in ethanol- and formaldehyde-fixed paraffin-embedded tissues. J Histochem Cytochem 1981; (in press).

${ }^{15}$ Brandtzaeg $P$. Conjugates of .immunoglobulin G with different fluorochromes II. Scand J Immunol $1973 ; 2: 333-48$.

16:Klockars M, Reitamo S. Tissue distribution of lysozyme in man. J Histochem Cytochem 1975; 12:93240.

17Erlandsen SL, Parsons JA, Taylor TD. Ultrastructural immunocytochemical localization of lysozyme in the Paneth cells of man. J Histochem Cytochem 1973; 22:401-13.

${ }^{18}$ Trier JS, Lorenzsonn V, Groehler K. Pattern of secretion of Paneth cells of the small intestine of mice. Gastroenterology 1967; 53:240-9. 
${ }^{19}$ Ahonen A, Penttilä A. Effects of fasting and feeding and pilocarpine on Paneth cells of the mouse. Scand J Gastroenterol 1975; 10:347-52.

${ }^{20}$ Barkla DH, Tutton PJM. Experimentally induced accumulation and depletion of Paneth cell granules (Abstract). J Anat 1974; 118:389.

${ }^{21}$ Wright N, Watson A, Morley A, Appleton D, Marks J, Douglas A, The cell cycle time in the flat (avillous) mucosa of the human small intestine. $G u t$ $1973 ; 14: 603-6$.

22 Weinstein WM. Epithelial cell renewal of the small intestinal mucosa. Med Clin N Am 1974; 58:137586.

${ }^{23}$ Mallas E, Terry JM, Asquith P, Cooke WT. Serum lysozyme in inflammatory bowel and coeliac disease. J Clin Pathol 1976; 29:598-600. 